\title{
Hemochromatosis and yersiniosis
}

PAUl C ADAMS, MD, JAMES GREGOR, MD

\begin{abstract}
Two patients with documented hemochromatosis and systemic infection with Yersinia enterocolitica are described. The first patient presented with $Y$ enterocolitica septicemia and an infected hip prosthesis which led to the diagnosis of hemochromatosis. The second patient was previously treated for $Y$ enterocolitica with antibiotics but did not recover fully until aggressive phlebotomy therapy was started. The simultaneous occurrence of these two uncommon diseases is related to the ability of the yersinia organism to thrive in the presence of large amounts of iron. The association between iron overload and susceptibility to yersinia infection is reviewed within the context of these two cases. Can J Gastroenterol 1990;4(4):160-162
\end{abstract}

Key Words: Hemochromatosis, Iron, Yersinia

\section{Hémochromatose et yersiniose}

RESUME: Le cas de deux patients présentant une hémochromatose et une infection systémique à Yersinia enterocolitica établies est décrit. Le premier souffrait d'une septicémie à $Y$ enterocolitica et d'une prothèse de la hanche infectée qui a conduit au diagnostic d'hémochromatose. Le second avait déjà été soumis à une antibiothérapie pour une infection à $Y$ enterocolitica mais ne s'était pas entièrement remis avant d'avoir subi une phlébotomie agressive. La survenue simultanée de ces deux maladies rares est liée à la capacité que l'organisme yersinia possède de se multiplier en présence de grandes quantités de fer. Le rapport entre une surcharge martiale et une infection à yersinia est examinée dans le contexte de ces deux cas.

University Hospital, London, Ontario

Correspondence and reprints: Dr Paul C Adams, Room 5-OF18, University Hospital, London, Ontario N6A 5A5. Telephone (519) 663-3513

Received for publication January 2, 1990. Accepted January 9, 1990
Y ERSINIA ENTEROCOLITICA IS AN enteric pathogen with a wide spectrum of manifestations. Because of a peculiarity in the internal iron metabolism of the organism, it cannot acquire iron readily, which is an essential growth factor for all bacteria. In the presence of an excess amount of iron, $\mathrm{eg}$, in hemochromatosis, a favourable milieu is created which greatly increases the virulence of the yersinia organism. The following report describes two patients with familial hemo. chromatosis in which yersinia infection occurred and eventually led to the diag. nosis in one patient.

\section{CASE HISTORIES}

Case 1: A 69-year-old retired farmer was admitted with a presenting complaint of diarrhea, fever, chills and my. algias. He had a past history of a right hip replacement one year prior to ad. mission and no history of liver disease or diabetes. Blood cultures were drawn as an outpatient and grew $Y$ enterocolitica and the patient was admitted to hospital. At the time of admission vital signs were normal. Hepatomegaly was 
TABLE 1

\section{Iron and yersinia infections}

Hemochromatosis (1-8)

Hemosiderosis (8-13)

Oral iron therapy (21)

Parenteral iron therapy $(19,20)$

Oral iron overdose $(22,23)$

Thalassemia (14-18)

Sideroblastic anemia (15)

Hemodialysis (19)

Deferoxamine therapy $(14-16,24)$

detected as well as marked pain and limited range of motion of the right hip prosthesis. The patient was treated with intravenous imipenem. The hip joint was surgically explored and a purulent exudate found in the joint space which also grew $Y$ enterocolitica. Laboratory investigations showed a hemoglobin of $13.4 \mathrm{~g} / \mathrm{dL}$, alanine aminotransferase $114 \mathrm{iu} / \mathrm{L}$, aspartate aminotransferase 70 $\mathrm{iu} / \mathrm{L}$, ferritin $3060 \mu \mathrm{g} / \mathrm{L}$, and transferrin saturation $78 \%$. A computed tomography scan of the abdomen showed increased density of the liver suggestive of iron overload, and a percutaneous liver biopsy confirmed a diagnosis of hemochromatosis with micronodular cirrhosis. Family investigations led to a similar diagnosis of hemochromatosis and cirrhosis in his 69-year-old brother. Weekly phlebotomy therapy was started and he had an uneventful recovery from his septicemia after two weeks of intravenous imipenem and three weeks of oral ciprofloxacin as an outpatient.

Case 2: A 60-year-old male presented to this institution on referral from a peripheral hospital with fever and chills and a blood culture positive for $Y$ enterocolitica. Two months previously he had experienced a diarrheal illness followed by more general systemic symptoms of fever, chills, lethargy and anorexia. Blood cultures at that time were also positive for $Y$ enterocolitica. He was treated in the referring centre with a course of intravenous gentamycin and his symptoms abated. Previous examination had revealed hepatomegaly and an elevation in liver enzymes and serum ferritin, and investigations led to a liver biopsy demonstrating hemochromatosis with micronodular cirrhosis. Family studies revealed several siblings with hemochromatosis. Pertinent past medical history included a 25 year history of osteoarthritis, primarily affecting the hands and knees, and recently diagnosed type II diabetes mellitus, well controlled on diet alone. Physical examination showed the patient to be febrile with a temperature of $37.5^{\circ} \mathrm{C}$, and hepatosplenomegaly was detected. Laboratory investigation revealed slight elevations in alanine aminotransferase and aspartate aminotransferase, 69 and $37 \mathrm{iu} / \mathrm{L}$, respectively, and an elevated serum ferritin of $3444 \mu \mathrm{g} / \mathrm{L}$.

Therapeutic phlebotomies were initiated on admission and three were performed over the patient's one week hospital stay. His fever subsided over the first three days with no antibiotic therapy.

The patient was discharged and continued to undergo phlebotomy twice weekly over the next eight months; he had no further recurrence of his diarrheal or febrile illnesses.

\section{DISCUSSION}

Yersinia infection manifesting as septicemia and peritonitis has previously been described in eight patients with hemochromatosis $(1-8)$, and in a wide variety of other clinical settings associated with iron overload (Table 1). Several patients with hemosiderosis (9-11) including Bantu hemosiderosis $(12,13)$ have been described with hepatic abscesses and septicemia. Multiple hepatic abscesses are perhaps the most common presentation of yersinia in the setting of iron overload (9).

Iron-loading anemias such as thalassemia and sideroblastic anemia have also been described with yersinia infections (14-18). An increased incidence of yersinia has been described in hemodialysis patients (19), which are often iron overloaded because of parenteral iron therapy. Parenteral iron therapy in newborns (20) has also been associated with yersinia infections. Multiple hepatic abscesses which grew $Y$ enterocolitica have been described in a patient who had been on long term oral iron therapy (21). Infants who had accidentally ingested large doses of oral iron have also developed severe yersinia infections $(22,23)$. The use of the chelating agent deferoxamine to remove excess iron has also resulted in yersinia infections in patients and in experimental animal studies $(16,24)$.

The association between iron overloaded states and infections with yersinia is likely related to the mechanism of iron accumulation and metabolism by the yersinia organism. Bacterial organisms normally obtain iron by the release of chelator substances called siderophores, which bind and solubilize iron before they re-enter the bacteria by receptor-mediated endocytosis $(25,26)$. $Y$ enterocolitica is unique because it lacks siderophores yet has receptors for them $(25,27,28)$. The most virulent strains of yersinia may have the ability to synthesize high molecular weight proteins which allow them to catch the iron bound to other iron-containing molecules such as transferrin, ferritin and lactoferrin (29). The chelating agent deferoxamine is a siderophore produced by Streptomyces pilosus and can be used by yersinia for the acquisition of iron $(16,24)$. It removes excess iron from tissues and provides $Y$ enterocolitica with iron in a soluble and easily assimilable form.

Experimental animal studies have shown that deferoxamine greatly enhanced the susceptibility of iron loaded mice to $Y$ enterocolitica and reduced the LD50 by over a millionfold (16).

In the first case, and in another case of hemochromatosis (1), the yersinia septicemia was the presenting symptom which led to the diagnosis of hemochromatosis. In the second case, phlebotomy therapy resulted in resolution of the infection without antibiotic therapy. Since yersinia infection is relatively uncommon (30), patients with systemic yersinia infections should undergo further investigation for conditions associated with pathological iron overload, and phlebotomy therapy should be instituted along with appropriate antimicrobial therapy.

ACKNOWLEDGEMENTS: Dr Adams acknowledges the support of the Medical Research Council of Canada and the Ministry of Health of Ontario, the advice and assistance of Dr PR Flanagan, Dr LS Valberg and Anne Kertesz, and the secretarial assistance of Cathy Brown. 


\section{REFERENCES}

l. Cauchie P, Vincken W, Peeters O, et al. Hemochromatosis and Yersinia enterocolitica. Dig Dis Sci 1987;32:1438.

2. Abbott M, Galloway A, Cunningham JL. Haemochromatosis presenting with a double Yersinia infection. J Infect 1986;13:143-5.

3. Capron JP, Capron-Chivrac D, Tossou $\mathrm{H}$, et al, Spontaneous Yersinia enterocolitica peritonitis in idiopathic hemochromatosis. Gastroenterology 1984;87:1372-5.

4. Jacquenod P, Poitrine A, Loiseau D, et al. Yersinia enterocolitica septicemia and idiopathic hemochromatosis Role of iron overload. Gastroenterol Clin Biol 1984;8:293-6.

5. VanLier TA, Legaaj MB, Roos J. A patient with liver abscesses due to infection with Yersinia enterocolitica. Ned Tijdschr Geneeskd 1983;127:293-5.

6. Imhoof B, Auckenthaler R. Septicemia caused by Yersinia entercolitica: Report of a case. Schweiz Med Wochenschr 1980;110:1115-7.

7. Reinicke V, Korner B. Fulminant septicemia caused by Yersinia enterocolitica. Scand J Infect Dis 1977;9:249-51.

8. Hassig A, Karrer J, Pusterla F. Pseudotuberculosis in man. Schweiz Med Wochenschr 1949;79:971-3.

9. Beeching NJ, Hart HH, Synek BJ, et al. A patient with hemosiderosis and multiple liver abscesses due to Yersinia enterocolitica. Pathology 1985;17:530-2.

10. Shibuya H, Ando M, Kuroda K, et al. Fatal Yersinia enterocolitica septicemia complicated by unique hemosiderosis. Acta Pathol Jpn 1988;38:1461-72.
11. Bloquiaux W. Multiple liver abscesses from Yersinia enterocolitica. Tijdschr Gastroenterol 1968;11:578-83.

12. Rabson AR, Koornhof JH, Norman J, et al. Hepatosplenic abscesses due to Yersinia enterocolitica. Br Med J 1972;4:341.

13. Rabson AR, Hallett AF, Koornhof HJ. Generalized Yersinia enterocolitica infection. J Infect Dis 1975;131:447-51.

14. Gallant T, Freedman $M H$, Vellend $H$, et al. Yersinia sepsis in patients with iron overload treated with deferoxamine. $N$ Engl J Med 1986;314:1643.

15. Chits HY, Flynn DM, Hoffbrand AV, et al. Infection with Yersinia enterocolitica in patients with iron overload. Br Med J 1986;292:97.

16. Robins-Browne RN, Prpic IK. Deferoxamine and systemic Yersiniosis. Lancet 1983;ii:1372.

17. Butzler JP, Alexander M. Segers A, et al. Enteritis, abscess and septicemia by Yersinia enterocolitica in a thalas. semic child. Contrib Microbiol Immunol 1979;5:292-7.

18. Hewstone AS, Davidson GP. Yersinia enterocolitica septicemia with arthritis in a thalassemic child. Med J Aust 1972;1:1035-8.

19. Boelaert JR, Van Landuyt HW, Valcke YJ, et al. The role of iron overload in Yersinia enterocolitica and Yersinia pseudotuberculosis bacteremia in hemodialysis patient. J Infect Dis 1987;156:384-7.

20. Barry DMJ, Reeve AW. Increased incidence of Gram-negative sepsis with intramuscular iron injection. Pediatrics 1977;60:908-11.
21. Leighton PM, MacSween HM. Yersinia hepatic abscesses subsequent to long term oral iron therapy. JAMA 1987;257:964-5.

22. Mofenson HC, Caraccio TR, Sharieff N. Iron sepsis: Yersinia enterocolitica septicemia possibly caused by an over. dose of iron. N Engl J Med 1987;316:1092-3.

23. Melby K, Slordahl S, Guttenberg T], et al. Septicemia due to Yersinia enterocolitica after oral overdoses of iron. Br Med J 1982;285:467-8.

24. Robins-Browne RM, Prpic JK. Effects of iron and deferoxamine on infections with Yersinia entercolitica. Infect Immunol 1985;47:774-9.

25. Perry RD, Brubaker RR. Accumulation of iron by Yersiniae. J Bacteriol 1979;137:1290-8.

26. Bullen JJ. The significance of iron in infection. Rev Infect Dis 1981;3:1127-38.

27. Heesemann J. Chromosomal-encoded siderophores are required for mouse virulence of enteropathogenic Yersinia species. FEMS Microbiol 1987;48:229-33.

28. Robins-Browne RM, Rabson AR, Koornhof HJ. Generalized infection with Yersinia enterocolitica and the role of iron. Contrib Microbiol Immunol 1979;5:277-82.

29. Carniel E, Antoine JC, Guiyoule A, et al. Purification, location and immunological characterization of the iron-regulated high molecular weight proteins of the highly pathogenic Yersiniae. Infect Immunol 1989;57:540-5.

30. Cover TL, Aber RC. Yersinia enterocolitica. N Engl J Med 1989;321:16-24. 


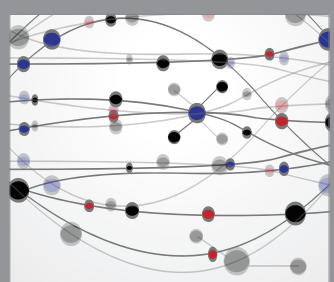

The Scientific World Journal
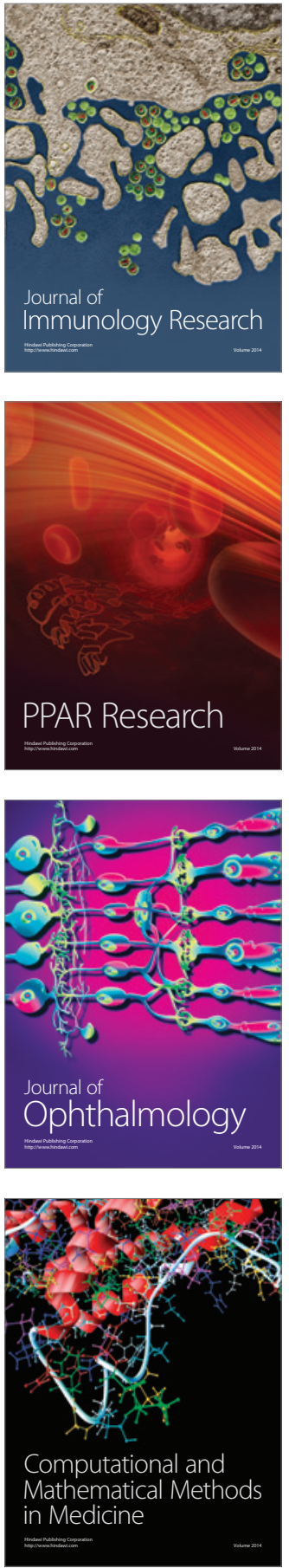

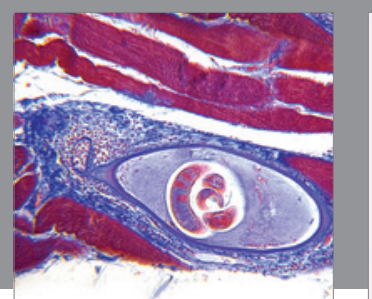

Gastroenterology Research and Practice

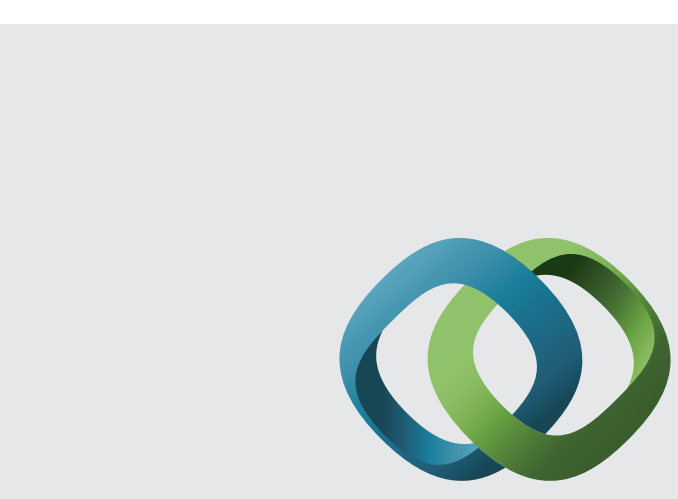

\section{Hindawi}

Submit your manuscripts at

http://www.hindawi.com
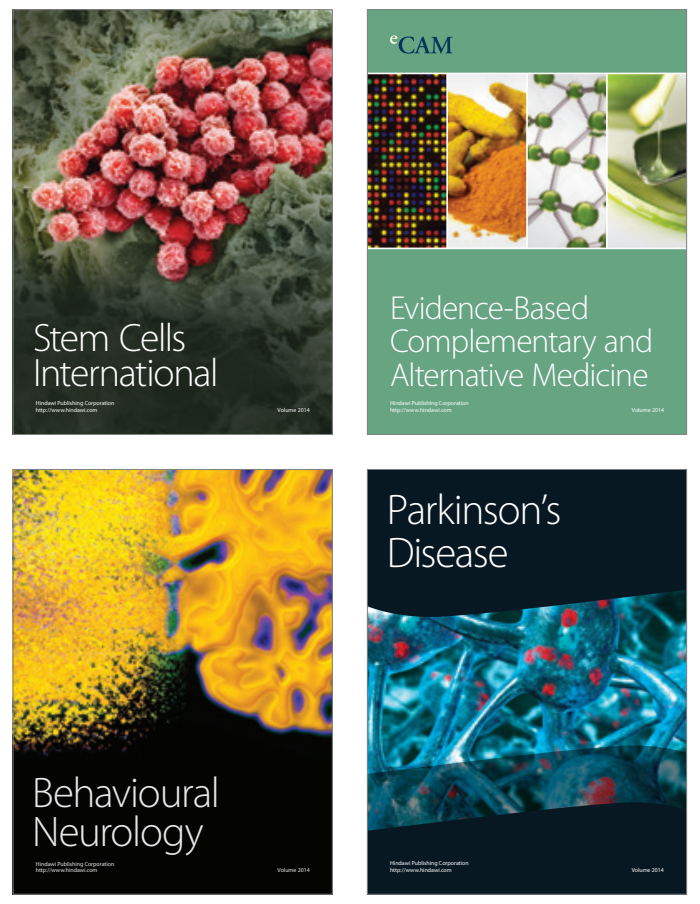
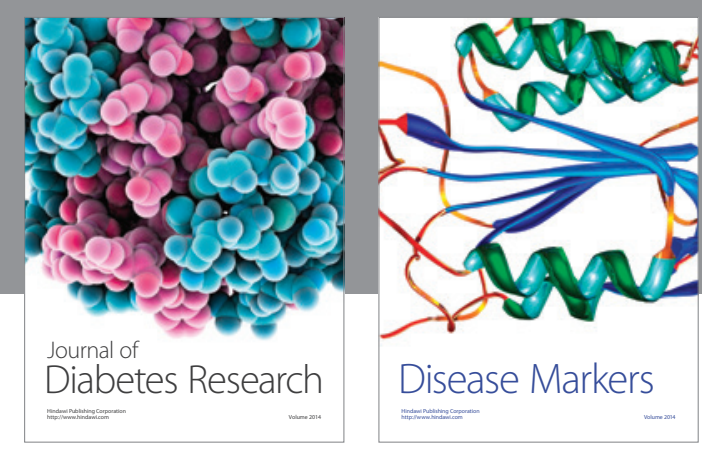

Disease Markers
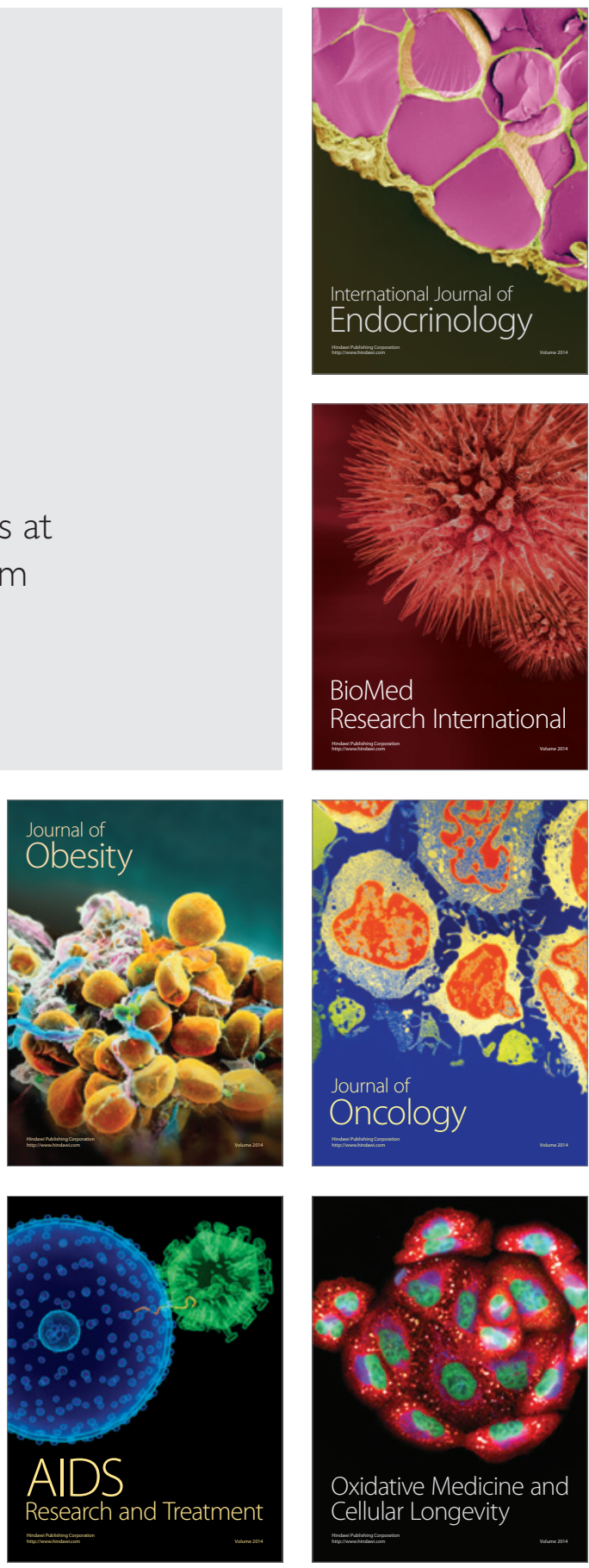